\title{
USO DE BIOMASSA RESIDUAL COMO ALTERNATIVA PARA A PRODUÇÃO DE CARVÃO ATIVADO
}

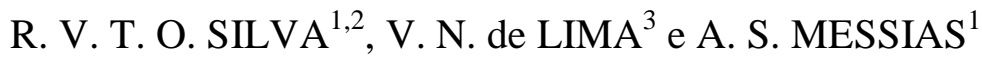 \\ ${ }^{1}$ Universidade Católica de Pernambuco, Centro de Ciências e Tecnologia \\ ${ }^{2}$ Mestrado em Desenvolvimento de Processos Ambientais; Bolsista Capes \\ ${ }^{3}$ Universidade Federal de Pernambuco, Departamento de Engenharia Química; Mestrado em \\ Engenharia Química; Bolsista PRH-28 ANP/MCTI \\ E-mail para contato: saconi@unicap.br
}

\begin{abstract}
RESUMO - O aumento das atividades tem elevado à produção e utilização de resíduos agroindustriais, como cascas e bagaços de frutas, denominada biomassa residual, que é uma importante fonte de matéria-orgânica renovável, com diversas utilizações possíveis. Nesse contexto, o uso de fibras, cascas e bagaços de frutas na preparação de carvão ativado (CA) se apresenta como alternativa econômica e ambiental, o que já é comprovado por diversos estudos. Assim, este estudo teve como objetivo avaliar a possibilidade de produção de CA a partir da mistura de fibra de coco seco, semente de acerola e bagaço de caju. Para tanto, foi realizado um delineamento experimental de blocos ao acaso, em cinco repetições, das relações percentuais coco/resíduo de 100/0 (somente a fibra de coco), 75/25, 50/50, 25/75 e 0/100 (somente resíduo). A fim de determinar a melhor mistura foi realizada uma etapa preliminar de análises, nessa etapa foram determinados: teor de carbono fixo, cinzas, umidade e material volátil, além da determinação do poder calorifico das misturas de resíduos. Na segunda etapa do estudo esta sendo realizado um experimento (escala de bancada) de carbonização, seguida de posterior ativação física (vapor d'água e $\mathrm{CO}_{2}$ ) das melhores amostras utilizando o método oficial de análise. Os dados preliminares sobre teor de carbono orgânico na biomassa apontam que há viabilidade no uso das misturas testadas e a segunda etapa do estudo esta em execução.
\end{abstract}

\section{INTRODUÇÃO}

Ao longo dos anos, os problemas ambientais vêm se agravando e tornando mais frequentes, principalmente decorrentes do crescimento populacional e elevadas atividades industriais. Esses fatores provocam expressivamente o crescimento do volume de resíduos industriais e de pósconsumos despejados no ambiente, superando a sua capacidade de promover a autodepuração e de prestar serviços ecossistêmicos essenciais à vida no planeta (Kunz, Peralta-Zamura, 2002; Pinto, 2012).

No Brasil, a agricultura e a agroindústria movimentam bilhões de reais na economia do país (Anuário, 2013) e, também, são responsáveis por muitos danos ambientais, pois existe pouca preocupação do setor em geral na geração, destinação e/ ou tratamento dos resíduos sólidos; na alta 


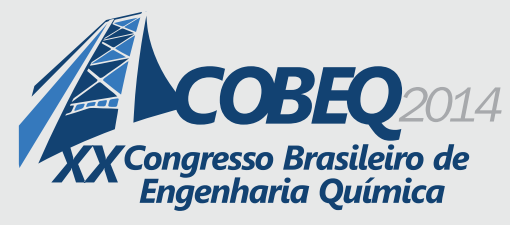

19 a 22 de outubro de 2014
Florianópolis/SC

geração em termos quantitativos e na sua degradabilidade, que, em certos casos, é muito lenta e gera inúmeros subprodutos tóxicos, cumulativos ou de difícil degradação (Godecke; Chaves; Naime, 2012).

Sendo um dos adsorventes mais eficazes para a separação e remoção de impurezas nos efluentes, o carvão ativado (CA) encontra-se em diversas aplicações na indústria de alimentos, produtos farmacêuticos, recuperação de solventes, tratamento de água potável, as células de combustível, químicas e outras indústrias de processo (Demiral et al., 2011).

Para a produção do CA existem dois métodos distintos: o térmico (físico) e ativação química. $\mathrm{O}$ processo térmico envolve a carbonização primária da matéria-prima (abaixo de $700^{\circ} \mathrm{C}$ ) seguida por gaseificação controlada a temperaturas mais elevadas em uma corrente de um gás oxidante (vapor, $\mathrm{CO}_{2}$, de ar ou uma mistura). A ativação química é realizada por impregnação do precursor com uma substância química $\left(\mathrm{H}_{2} \mathrm{SO}_{4}, \mathrm{H}_{3} \mathrm{PO}_{4}, \mathrm{ZnCl}_{2}\right.$, hidróxidos de metais alcalinos), em seguida, tratamento térmico a temperaturas moderadas $\left(400-600^{\circ} \mathrm{C}\right)$ em um só processo (Demiral et al., 2011). Contudo, segundo Florido (2004), a escolha do material mais apropriado para a produção será determinante para um controle das características finais do CA e o uso de resíduos, com elevado teor de carbono em sua estrutura, torna-se uma alternativa de bastante interesse.

Nesse contexto, estudos recentes têm apontado à possibilidade de produção de CA a partir do uso de casca de coco (Fernandes, 2010); no entanto não há estudos sobre a mistura da fibra da casca do coco seco com outros resíduos para essa finalidade.

Assim o objetivo desse trabalho é avaliar a viabilidade do uso de resíduos (fibra/bagaço/sementes) de coco, acerola e caju na produção de carvão ativado, a fim de visar à minimização e mitigação dos poluentes, estimular o uso de fontes alternativas para a produção de carvão ativado, contribuir para a diminuição de custos econômicos e preservação do meio ambiente.

\section{MATERIAL E MÉTODOS}

Esse trabalho foi conduzido em forma de experimento sendo realizado em duas etapas: preparação e caracterização preliminar das misturas de resíduos; e carbonização e ativação da melhor mistura de resíduos a fim de produzir carvão ativado.

Na primeira etapa ocorreu a coleta da matéria-prima, casca do coco seco e resíduos de caju e acerola (bagaço e sementes). A casca de coco foi coletada nos próprios locais de venda de água de coco, descartando-se aquelas de coloração marrom, porque apresentam maior dificuldade para serem processadas e os resíduos de caju e acerola foram obtidos nas indústrias de processamento de polpas e sucos local. Após a coleta os resíduos foram triturados uma máquina desintegradora/trituradora de forragem para obtenção de material uniforme. Após o desfibramento, o material passou pela secagem até atingir de 15 a $20 \%$ de umidade e posteriormente o material foi passado em peneira de 60 mesh para obtenção de granulometria equivalente de todos os resíduos. O delineamento experimental utilizado foi o de blocos ao acaso, com cinco repetições, com a relação percentual de coco/resíduo igual a 100/0 (somente fibra de coco), 75/25, 50/50, 25/75 e 0/100 (somente resíduo). Para as análises preliminares, que consta na primeira etapa do estudo, foi determinada a umidade na base seca, teor de 
cinza \%, material volátil \% e carbono fixo \%, segundo a norma ASTM D-1762/64, e o poder calorífico, segundo a norma ABNT-NBR 8633/84, das diversas misturas.

Para a determinação da melhor mistura de resíduos foi adotado o uso da técnica de PCA como alternativa de melhor expressão dos resultados devido à quantidade de parâmetros analisados. Para essa análise, os valores das variáveis analisadas foram utilizados como dado de entrada e o algoritmo adotado para o pré-processamento da matriz de dados foi o auto-escalonamento. Todos os cálculos foram realizados com o uso do software Statistica 8.0 (2007). Posteriormente, foi avaliada a variação das determinações (cinza, carbono fixo, material volátil e poder calorífico) entre as misturas de fibra de coco e os resíduos testados no estudo, em termos da diferença fracional dos teores.

Na segunda etapa do estudo, de posse dos dados preliminares das melhores mistura de resíduos, levando-se em consideração, em primeiro lugar, o teor de carbono orgânico das misturas, será realizada a carbonização da matéria-prima selecionada dentre as preliminarmente testadas em mufla com atmosfera inerte de $\mathrm{N}_{2}$, seguida por ativação física (vapor d'água e $\mathrm{CO}_{2}$ ).

\section{RESULTADOS E DISCUSSÃO}

Para melhor compreensão dos dados apresentadas neste texto foi elaborada a legenda a seguir:

\begin{tabular}{ll}
\hline Relação percentual coco + resíduo & Legenda \\
\hline $100 \%$ de fibra de coco (testemunha do coco) & $\mathrm{CT}$ \\
$75 \%$ de fibra de coco $+25 \%$ de resíduo & $\mathrm{CR} 1$ \\
$50 \%$ de fibra de coco $+50 \%$ de resíduo & $\mathrm{CR} 2$ \\
$25 \%$ de fibra de coco $+75 \%$ de resíduo & $\mathrm{CR} 3$ \\
$100 \%$ de caju (testemunha do caju) & $\mathrm{CjT}$ \\
$100 \%$ de acerola (testemunha da acerola) & $\mathrm{AT}$ \\
\hline Determinações realizadas & Legenda \\
\hline Umidade percentual - base seca & $\mathrm{U}$ \\
Cinza percentual & $\mathrm{C}$ \\
Material Volátil percentual & $\mathrm{MV}$ \\
Carbono Fixo percentual & $\mathrm{CF}$ \\
Poder Calorífico (g/cal.K) & $\mathrm{PC}$ \\
\hline
\end{tabular}

Para a observação do comportamento das misturas de resíduos como alternativa para a produção de carvão, foi utilizada a análise de componentes principais. Para essa análise, as matrizes de dados formadas pelas médias dos valores de umidade (\%) na base seca, cinza (\%), material volátil $(\%)$, carbono fixo $(\%)$ e poder calorífico (g/cal.K) foram colocadas como dado de entrada em contraposição com as misturas de fibra de coco e resíduos testadas; e o algoritmo adotado para o préprocessamento das matrizes de dados das misturas e determinações foi o autoescalonamento.

A variância percentual acumulada (Sharaf et al., 1986) encontrada na análise estatística das determinações realizadas para as diferentes misturas de fibra de coco seco. Na Figura 1 (a e b), são apresentados os pesos e os escores para os dois primeiros componentes principais das médias das 
determinações realizadas para a seleção da melhor mistura de fibra de coco com bagaço de caju para a produção de carvão ativado. A variância percentual acumulada (Sharaf et al., 1986) encontrada na análise estatística das determinações realizadas para as diferentes misturas de fibra de coco com bagaço de caju e determinada pelos dois primeiros componentes principais foi de 91,78\%.

No gráfico dos escores, que mostra a correlação entre as determinações codificadas quanto às misturas de fibra de coco com bagaço de caju (CB), (Figura 1b), pode ser observada ao longo da primeira componente principal (PC1) que para as diferentes misturas (CCj1, CCj2 e CCj3) houve uma maior presença de cinza e que não ocorreu uma diferença significativa entre as amostras, ficando todas agrupadas ao longo da PC1, contudo a amostra CCj3 (25\% de fibra de coco $+75 \%$ de resíduo de caju) apresentou o melhor resultado com melhor teor de carbono fixo percentual. Contudo demonstra-se que a seleção da melhor mistura de fibra de coco com bagaço de caju, quando analisadas essas proporções $(75 / 25 ; 50 / 50 ; 25 / 75)$, não pode ser realizada partindo apenas do princípio de comparação entre as amostras.

$\mathrm{Na}$ Figura 1a, através da PC1, pode ser observado um contraste entre as variáveis $\mathrm{CF}$ e $\mathrm{C}$ e uma correlação positiva entre a CF e MV e entre C, U e PC. Demonstrando, mais uma vez, que quanto maior for a concentração de carbono na estrutura do material, menor será a concentração de material inorgânico da estrutura.

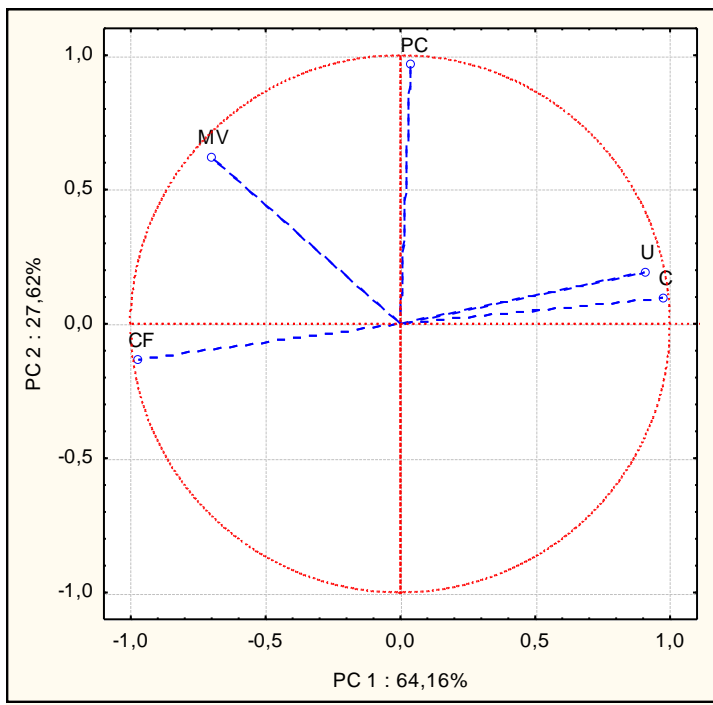

(a)

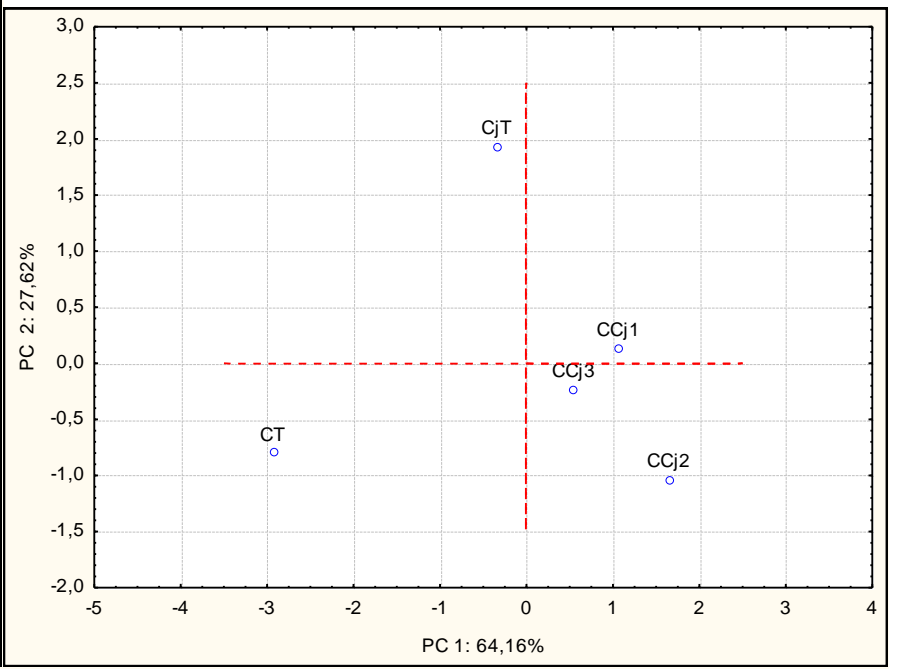

(b)

Figura 1 - Gráfico dos pesos (a) e dos escores (b) para as duas componentes principais para mistura de fibra de coco com bagaço de caju

Na Figura 2 ( $a$ e b), são apresentados os pesos e os escores para os dois primeiros componentes principais das médias das determinações realizadas para a seleção da melhor mistura de fibra de coco com semente de acerola para a produção de carvão ativado. A variância percentual acumulada (Sharaf et al., 1986) encontrada na análise estatística das determinações realizadas para as diferentes 
misturas de fibra de coco com bagaço de caju e determinada pelos dois primeiros componentes principais foi de $82,17 \%$.

No gráfico dos escores, que mostra a correlação entre as determinações codificadas quanto às misturas de fibra de coco com semente de acerola (CA), (Figura 2b), pode ser observada ao longo da primeira componente principal (PC1), um contraste entre a amostra com maior teor de semente de acerola na mistura com fibra de coco (CA3 $-25 \%$ de fibra de coco $+75 \%$ de resíduo de acerola) e as amostras com menores relações percentuais de mistura de fibra de coco com casca de banana (CB1 $75 \%$ de fibra de coco $+25 \%$ de resíduo de acerola - e CB2 $-50 \%$ de fibra de coco $+50 \%$ de resíduo de acerola), mostrando que para mistura fibra de coco com sementes de acerola quanto maior for à relação percentual entre a mistura (tendendo para o lado da acerola), melhor será a amostra para produção de carvão ativado. Pode ser observado que a amostra AT (testemunha da acerola) apresentou excelente resultado, com um bom poder calorífico, alto teor de carbono fixo e o menor teor de cinza em relação aos demais tratamentos utilizados no experimento, e que a amostra CT (testemunha do coco), apenas neste caso, apresentou um teor de cinza superior e de carbono fixo inferior ao da testemunha do resíduo e das misturas (CA1, CA2 e CA3).

Na Figura 2a, através da PC1, pode ser observado um contraste entre a $\mathrm{C}$ e todas as demais variáveis estudadas ( $\mathrm{CF}, \mathrm{MV}, \mathrm{PC}$ e $\mathrm{U})$, e uma correlação positiva entre a $\mathrm{CF}$, MV e PC, demonstrando que para a mistura de fibra de coco com resíduos de acerola a viabilidade maior encontra-se nas misturas onde a predominância é de resíduo de acerola.

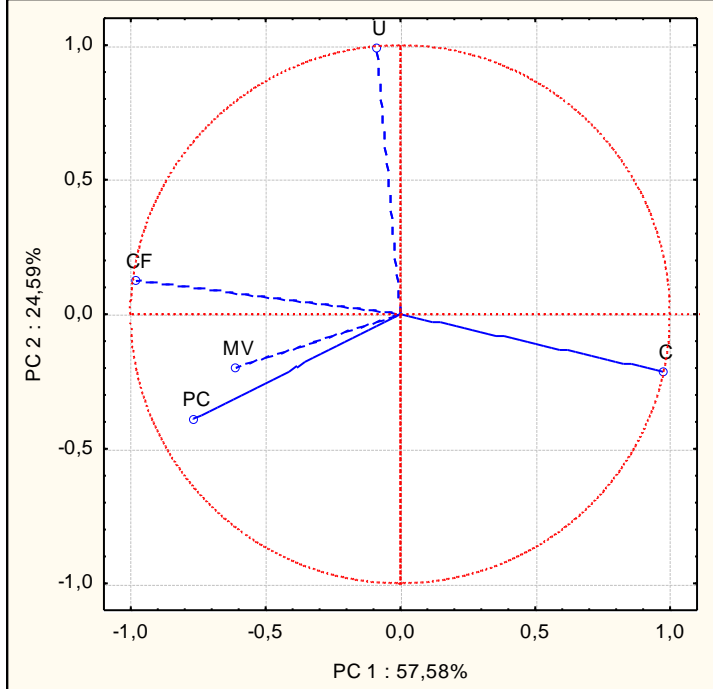

(a)

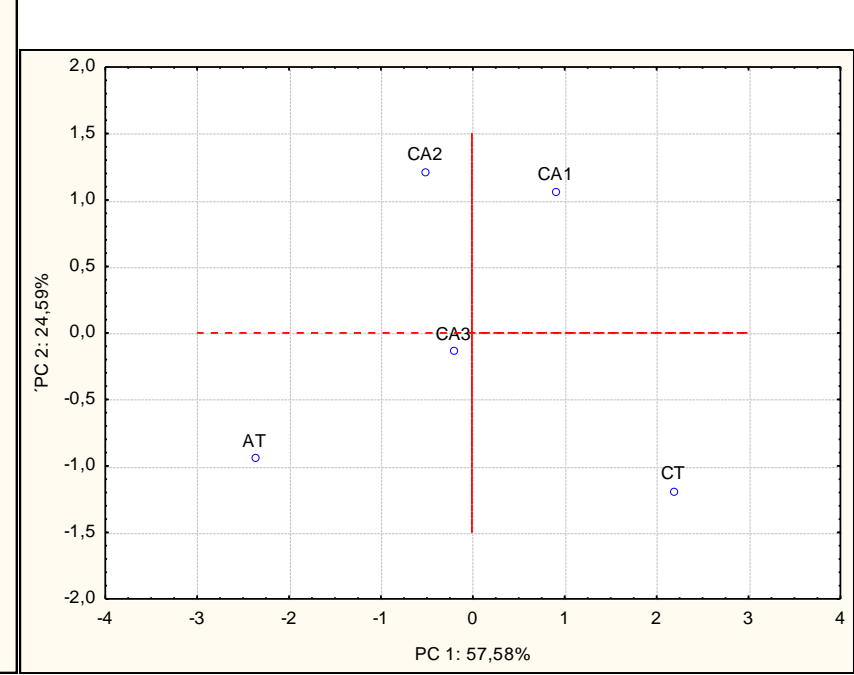

(b)

Figura 2 - Gráfico dos pesos (a) e dos escores (b) para as duas componentes principais para mistura de fibra de coco com sementes de acerola

O cálculo da diferença fracional (DF) foi utilizado para quantificar os resultados obtidos a partir da análise de componentes principais. Consiste em determinar quanto a amostra analisada (Ci) se assemelha à amostra tida como padrão $(\mathrm{Co})$, através da equação 1: 


$$
D F=\frac{C i-C o}{C o} \times 100
$$

Os dados para os teores de cinza (\%), material volátil (\%), carbono fixo (\%) e poder calorífico (g/cal.K) obtidos para as misturas de fibra de coco com os diferentes resíduos (resultados obtidos com uma média de cinco repetições), observando-se a interação entre a testemunha do coco (CT) e as misturas de fibra de coco com o resíduo de caju e sua testemunha $(\mathrm{CjT})$; e entre a testemunha do coco (CT) e as misturas de fibra de coco com o resíduo de acerola e sua testemunha (AT), a fim de determinar o comportamento das misturas como matéria-prima para a produção de carvão ativado.

Na Tabela 1, estão apresentados os dados de cinza, material volátil, carbono fixo e poder calorífico para a testemunha da fibra de coco (CT), que foram utilizados como referências para avaliar a diferença fracional entre as misturas de fibra de coco com resíduos para produção de carvão ativado (DF total).

Tabela 1 - Dados obtidos para fibra de coco seco

\begin{tabular}{|l|c|c|}
\hline Determinações & Unidade & Fibra de coco seco \\
\hline Cinza & & 7,60 \\
\hline Carbono fixo & \multirow{2}{*}{$\%$} & 86,03 \\
\hline Material volátil & & 6,12 \\
\hline Poder calorífico & $\mathrm{g} / \mathrm{cal} . \mathrm{K}$ & 50,48 \\
\hline
\end{tabular}

Na Tabela 2, estão apresentados os valores para cinza, carbono fixo, material volátil e poder calorífico, e suas respectivas diferenças fracionais entre as misturas de fibra de coco com os diferentes resíduos (DF) e os valores mostrados para a fibra de coco seco (DF total) (Tabela 1).

Tabela 2 - Diferenças fracionais para as diferentes misturas de fibra de coco com resíduos

\begin{tabular}{|c|c|c|c|c|c|c|}
\hline Amostra & $\begin{array}{l}\text { Cinza } \\
(\%)\end{array}$ & DF \% & DF total & $\begin{array}{l}\text { Carbono fixo } \\
(\%)\end{array}$ & DF \% & DF total \\
\hline $\mathrm{CT}$ & 7,60 & & & 86,03 & & \\
\hline $\mathrm{CCj} 1$ & 34,64 & 355,93 & 355,93 & 57,87 & $-32,74$ & $-32,74$ \\
\hline $\mathrm{CCj} 2$ & 35,02 & 360,93 & 360,93 & 58,46 & $-32,04$ & $-32,04$ \\
\hline $\mathrm{CCj} 3$ & 24,86 & 227,21 & 227,21 & 67,68 & $-21,33$ & $-21,33$ \\
\hline $\mathrm{CjT}$ & 25,14 & 230,83 & 230,83 & 67,31 & $-21,75$ & $-21,75$ \\
\hline Amostra & $\begin{array}{l}\text { Material volátil } \\
(\%)\end{array}$ & DF \% & DF total & $\begin{array}{l}\text { Poder calorífico } \\
\text { (cal/g.K) }\end{array}$ & DF \% & DF total \\
\hline $\mathrm{CT}$ & 6,12 & & & 50,48 & & \\
\hline $\mathrm{CCj} 1$ & 5,85 & $-4,43$ & $-4,43$ & 52,30 & 3,62 & 3,62 \\
\hline $\mathrm{CCj} 2$ & 4,98 & $-18,56$ & $-18,56$ & 51,29 & 1,61 & 1,61 \\
\hline $\mathrm{CCj} 3$ & 5,56 & $-9,06$ & $-9,06$ & 52,51 & 4,03 & 4,03 \\
\hline $\mathrm{CjT}$ & 6,21 & 1,51 & 1,51 & 60,23 & 19,32 & 19,32 \\
\hline
\end{tabular}




\begin{tabular}{|c|c|c|c|c|c|c|}
\hline Amostra & $\begin{array}{l}\text { Cinza } \\
(\%)\end{array}$ & DF \% & DF total & $\begin{array}{l}\text { Carbono fixo } \\
(\%)\end{array}$ & DF \% & DF total \\
\hline $\mathrm{CT}$ & 7,60 & & & 86,03 & & \\
\hline CA 1 & 5,65 & $-25,68$ & $-25,68$ & 87,70 & 1,95 & 1,95 \\
\hline CA 2 & 3,98 & $-47,57$ & $-47,57$ & 88,88 & 3,32 & 3,32 \\
\hline CA 3 & 5,12 & $-32,56$ & $-32,56$ & 87,93 & 2,21 & 2,21 \\
\hline $\mathrm{AT}$ & 2,93 & $-61,49$ & $-61,49$ & 90,37 & 5,05 & 5,05 \\
\hline Amostra & $\begin{array}{l}\text { Material volátil } \\
(\%)\end{array}$ & DF \% & DF total & $\begin{array}{l}\text { Poder calorífico } \\
(\text { cal/g.K) }\end{array}$ & DF \% & DF total \\
\hline $\mathrm{CT}$ & 6,12 & & & 50,48 & & \\
\hline CA 1 & 5,88 & $-3,85$ & $-3,85$ & 52,67 & 4,35 & 4,35 \\
\hline CA 2 & 6,36 & 3,98 & 3,98 & 50,27 & $-0,40$ & $-0,40$ \\
\hline CA 3 & 6,39 & 4,40 & 4,40 & 53,08 & 5,15 & 5,15 \\
\hline AT & 6,32 & 3,40 & 3,40 & 57,92 & 14,75 & 14,75 \\
\hline
\end{tabular}

$\mathrm{DF}=$ diferença fracional de cada mistura, em relação a testemunha da fibra de coco (TC)

DF total $=$ diferença fracional de cada mistura, em relação aos dados da fibra de coco (Tabela 1)

Pela Tabela 2 comprova-se a relação inversamente proporcional entre o teor de carbono fixo \% e o teor de cinza \% observada no método de PCA, percebida em relação à diferença fracional entre as misturas. Para a mistura de fibra de coco com resíduos de caju observa-se que todas as misturas de resíduos de caju apresentam um baixo teor de carbono e um alto teor de cinza, e isso acontece porque as altas concentrações de carbono estrutural e o baixo teor de matéria inorgânica (cinza) são de grande importância pra produção do CA (Couto, 2009). Observa-se, também, que em nenhuma amostra analisada os valores de material volátil superaram a marca de $7 \%$ e que para esse parâmetro existe uma relação diretamente proporcional com o carbono fixo em todos os casos analisados, pois nota-se que a diferença fracional total (DF total) para o material volátil acompanha as elevações e decaimentos da DF total do carbono fixo. Todas as misturas de fibra de coco com resíduos apresentam resultados promissores, no que se refere a umidade do resíduo, já que baixos teores de água foram encontrados nas amostras.

\section{CONSIDERAÇÕES FINAIS}

Diante do exposto, observa-se que para as misturas de fibra de coco com os diversos resíduos as diferentes misturas apresentaram resultados promissores, com alto teor de carbono fixo e baixo teor de cinza, sendo que para mistura de fibra de coco com resíduos de caju o melhor resultado foi obtido na mistura CCj3 (25\% de fibra de coco com $75 \%$ de bagaço de caju) e para mistura de fibra de coco com resíduos de acerola o melhor resultado foi obtido na mistura CA2 (50\% de fibra de coco com $50 \%$ de semente de acerola), sendo considerado o resultado mais promissor do experimento com 3,99\% de cinza e 88,88 \% de carbono fixo na estrutura, o que garantiria um carvão ativado de melhor qualidade. 
E observa-se, ainda, que o resíduo de acerola apresentou um baixo teor de cinza e material volátil, e um excelente (alto) teor de carbono fixo, sendo superior a testemunha do experimento, fibra de coco, indicando que esse resíduo sozinho pode ser utilizado para produção de carvão ativado, respeitando o volume de resíduos demandado na produção.

Assim, na segunda fase do trabalho (carbonização e ativação) seguem-se utilizando as misturas: CCj3, CA2 e AT.

\section{REFERENCIAS}

AMERICAN SOCIETY FOR TESTING AND MATERIALS - ASTM. D 1762/64 (Reapproved 1977). p.578. 1964.

ANUÁRIO Brasileiro da Fruticultura. Santa Cruz do Sul: Gazeta Santa Cruz, 2013. 140 p.

ASSOCIAÇÃO BRASILEIRA DE NORMAS TÉCNICAS - ABNT. NBR 8633/84. Determinação do poder calorífico superior. 13p. 1984.

COUTO, G. M. Utilização de serragem de Eucalyptus sp. na preparação de carvões ativados. Lavras: UFLA, 2009. 89p.

DEMIRAL, H.; DEMIRAL, I.; KARABACAKOGLU, B.; TÜMSEK, F. Production of activated carbon from olive bagasse by physical activation. Icheme, v. 89, p. 206-213, 2011.

FERNANDES, K. A. D. Uso de carvão ativado de endocarpo de coco no tratamento de água. Revista da graduação da PUCRS, Porto Alegre, v. 3, n. 2, 2010. Disponível em: <http://revistaseletronicas.pucrs.br/ojs/index.php/graduacao/article/viewFile/7906/5591>. Acesso em: 20 março 2012. 17p.

FLORIDO, P. Avaliação de tecnologias visando reuso de efluentes: adsorção em carvão ativado. Efluentes hídricos: resultados em P\&D, Gerencia de Biotecnologia e Tratamento Ambientais, Petrobras, Rio de Janeiro, n. 8, set. 2004.

GODECKE, M. V.; CHAVES, I. R.; NAIME, R. H. Gestão de resíduos sólidos urbanos no Brasil: o caso de Canoas, RS. Revista Eletrônica em Gestão, Educação e Tecnologia Ambiental. v.7, n. 7, p. 1430-1439, mar-ago, 2012.

SHARAF, M. A.; ILlMAN, D. L.; KOWALSKI, B. Chemometrics, New York: Wiley, 1986.

STATISTICA 8.0 Statistica. StatSoft. (software). 2007.

KUNZ, A.; PERALTA-ZAMORA, P. Novas tendências no tratamento de efluentes têxteis. Revista Quimica Nova, v. 25, n. 1, p. 78-82, 2002. 